\title{
Incredible Ottoman Projects
}

\author{
Turan Şahin \\ Istanbul: Blue Dome Press, 2013. 127 pages (full color)
}

When the term Ottoman architecture is used, the immediate image that comes to mind is that of the multitudes of mosque and religious buildings in Turkey and the Ottoman Empire. One with a more in-depth knowledge of this field may think of the prolific architect Sinan (d. 1588) and his hundreds of purpose-built works. However, this is not another book on Ottoman mosques and pious foundations, but rather a focused collection of the empire's oftenoverlooked civic works, some of which demonstrate engineering innovations in design. The empire's geographical proximity to Europe gradually caused it to look westward for aspiration and engendered a palpable reflection of European influence in those of its architectural and infrastructure designs that were the result of commissioning European experts to keep Istanbul and the empire abreast of the latest innovations.

This book is divided into thirty-five short sections, ranging from two to fourteen pages each, that consider particular urban, architecture, or infrastructural initiatives. Each section bears the name of the project in question, which is amply illustrated with historical drawings (i.e., maps, urban plans, perspectives rendered in watercolor, sections, and structural details), historical photographs, and relevant textual documents. However, almost no attempt has been made to connect them to each other or to a larger thesis. And despite the introduction's portrayal of a wealthy, powerful, and vast empire with imperial investment in built innovations to improve the city, no indication is given as to the variety and breadth of the projects to be covered.

An in-depth history of each one's initiation is outlined, often revolving around an enlightened Ottoman sultan or an equally enlightened and forwardthinking European architect, urban planner, or engineer with occasional international backing. The majority of these projects were never completed due to such international crises as war, natural disasters (e.g., earthquakes), the lack 
of funding, or simply the lack of technological expertise for particularly ambitious and large-scale projects. The watercolor perspectives, technical sections, and details, along with the proposed urban plans, illustrate some truly aspiring attempts to modernize and effectively connect the disparate parts of the city that are divided by continents and canals.

As such, the book promised to be a valuable collection of historical data on otherwise unknown projects and the variety of international experts involved. However, a number of structural issues impede a complete reading of this book. As mentioned earlier, the introduction does not frame the material. Moreover, the lack of a coherent system that organizes the projects (e.g., they are not ordered chronologically or thematically by infrastructure type) leaves the reader at a loss as to the connection among them. Additionally, the book ends without a conclusion or a closing chapter, thereby missing the opportunity to reflect upon these projects' meanings and impacts.

Internally, each section has various issues. The short text for each project is not clearly framed with respect to just how much - if any - of the project was completed. Rather, the reader is taken along a detailed journey of each one's step-by-step process of initiation, as well as the disasters/crises/issues that aborted it, but then is left to wonder about its fate. Occasionally a contemporary photograph will show that a particular project (very few from the thirty five discussed) was somehow constructed; however, the particulars are left unaddressed. Also of serious consequence is the desperate need for language editing, given that this is a translated (from the Turkish) text. At times the shift in syntax, tense, or even grammatical errors make for very difficult reading.

Possibly the most promising aspect is that the author has collected historical drawings and photographs from various sources and reproduces them in color. It is disappointing that some of them are of low resolution, which results in highly pixelated reproductions, and that other images have been altered to fit into the book's highly stylized graphics (e.g., the inversion as well as the partial coloring of photographs).

Specific projects reviewed include revitalization plans for the Hippodrome, Beyazit Square, and Valide Sultan - each of which included widening the plazas (including landscaping) and demolishing such major landmarks as the Sultan Ahmed mosque. Other projects included plans for tunnels, metro infrastructure, monumental bridges spanning the Golden Horn, and various canal projects. There were also early Ottoman attempts to construct what would later become the Suez Canal. Partially completed ambitious railroad projects are outlined, as is the Galata Tower proposal. 
Other projects, among them river expansion, desalination, village establishment, "sports holiday" resorts, and even machine design projects, are examined in detail.

From the specific histories and anecdotes told about each undertaking, an example of overarching ideas and themes emerge. Certain sultans had fascinating ambitions. For example, Abdul Hamid (r. 1876-1909) dreamed of modernizing Istanbul with the help of European experts. The of European architects and engineers, going as far back as the stillborn design attempts of Leonardo Da Vinci and the unsuccessful commissioning of Michelangelo, set the tone for many of the abandoned projects that would follow. Later on, during the nineteenth century, such French architects and engineers as Antoine Bouvard and Fuigene Henri Gavand, along with the Italian architect Raimondo Tommaso D'Aronco, and others proposed urban plans and urban infrastructure initiatives both within Istanbul and the Ottoman Empire at large. The trajectory of their roles and how each one attempted to shape the city and beyond is a story in itself worth telling; unfortunately, this volume does not provide it.

The historical data, drawings, and photographs, and other material offered will be useful to students and scholars interested in the specific area of Ottoman infrastructure construction or Ottoman modernization initiatives. Only such a specific audience would appreciate and utilize the material in the book, which has not yet been adequately analyzed. Like the stillborn projects it examines, this book seems to be incomplete, an ill-fated collection with ambitious and rich material that has not been fully developed in a coherent manner.

Tammy Gaber Assistant Professor, School of Architecture Laurentian University, Sudbury, ON, Canada 